\title{
LIBERDADE E INTERDIÇÃO
}

Ivia Alves

RESUMO: Em uma sociedade que se diz igualitária e libertária, o sexismo dificultou a criação literária realizada pelas mulheres, cujo papel limitava-se ao ambiente privado. Lutando pela liberdade de se expressar através da literatura e de publicar suas produções, independentemente de proteção, escritoras baianas vão, de estratégia em estratégia, driblando esses impedimentos, mas, só com o feminismo, elas ganham a sua própria voz.

PALAVRAS-CHAVE: Literatura de autoria feminina. Códigos e normas sociais. Limites da criação. Interdição.

ABSTRACT: In a society like ours where equality and freedom does not actually exist, sexism meant an obstacle to artistic creation held by women, whose social role was limited to private sphere. Regardless of protection, in this context, the bahian women writers were fighting for freedom to express themselves through writing and publishing their productions. To do so, they created strategies to circumvent these impediments imposed by society. However, it was only with feminism that they gain own voice.

KEY WORDS: Writing of female authorship. Social codes. Interdiction and freedom

A Modernidade, vista como um sistema de novas normas nos campos econômico, político, social e cultural, é bem diferente do sistema anterior (da aristocracia,de reinos, principados etc). Esta Modernidade que, como ondas, abrange a Europa e suas colônias nas Américas, teve como lema as palavras disseminadas pelo Iluminismo e que desembocaram na Revolução Francesa - "liberdade, fraternidade e igualdade". Mas, desde o entreato entre as ideias de uma nova sociedade e a Revolução francesa, a mulher não se via contemplada e já se ouvia a voz da mulher evidenciando suas reivindicações: igualdade na educação e como cidadã.

É bem verdade que a Revolução Francesa e seus desdobramentos pelo Ocidente construiu outra sociedade, moldada à feição da burguesia que consolidou e criou instituições e dentre elas a família nuclear. Seus fundamentos passaram a ser difundidos pelas artes e principalmente a literatura tomou a dianteira, com a entrado do novo gênero romance, e a poesia, descartando os velhos modelos que buscavam temática e ideias na literatura grega e romana, passava a ser o arauto da individualidade do artista que descrevia seus sentimentos e desejos. Essas novas formas de expressão eram caras aos leitores burgueses É bem verdade que a Revolução Francesa e seus desdobramentos pelo Ocidente construíram outra sociedade, 
moldada à feição da burguesia, que consolidou e criou instituições, entre elas, a família nuclear. Seus fundamentos passaram a ser difundidos pelas artes e a literatura tomou a dianteira, com a entrado do novo gênero em suas horas de lazer, que espraiaram o primeiro movimento artístico da classe - o movimento romântico.

Enquanto esta nova sociedade se delineava, propalando a liberdade para todos e o novo em todos os sentidos, isto não abrangeria, na realidade, toda a população, nem mesmo a classe burguesa e instruída. Ficaram relegadas as manifestações artísticas e científicas das mulheres.

Hoje, as pesquisas arqueológicas realizadas pelas feministas e outros segmentos evidenciam que muitas mulheres se aventuraram pelo campo do conhecimento e das artes, mas não tiveram reconhecimento, e suas obras foram, com o tempo, sendo esquecidas de ser mencionadas, colocando-as numa espécie de limbo ${ }^{1}$.

Esta introdução nos ajuda a situar o lugar da mulher na sociedade moderna, cujo único papel estava limitado ao ambiente familiar. Seja ele como filha, esposa, viúva ou solteira (a tia), essa sociedade insistia na sua permanência na casa. Para ela, a casa e suas responsabilidades não obrigavam, segundo a visão burguesa, uma sólida instrução para que ela fosse independente ou buscasse uma profissão que pudesse, em ocasiões difíceis, ajudá-la economicamente. Encerrada nesse espaço protegido, aquelas que transgrediam não eram bem vistas e o tempo (nesses 300 anos) as esqueceu, talvez pelos maus exemplos que elas significariam para as gerações seguintes. Mas não podemos esquecer que várias delas se insurgiram contra essa interdição. Observamos que muitas inglesas e alemãs, pela própria religião, eram instruídas e trabalhavam. Muitas foram as ilustradoras dos livros de ciências naturais, visto que naquela época não havia fotografia, outras não só se tornaram professoras em seus países, mas se aventuraram pelas colônias, tornando-se preceptoras de jovens e crianças das classes abastadas e latifundiárias.

No entanto, uma das primeiras manifestações escritas, que sobreviveu até os dias atuais e se pode denominar um grito feminista, aparece por volta de 1792 - o livro de Mary Wollstonecraft intitulado Uma defesa dos direitos da mulher (Vindication of the Rights of Woman). Uns quatro ou cinco anos antes, a autora, que fundou escolas para moças, já havia escrito um livro (Reflexões sobre a educação das filhas/Thoughts on the Education of

\footnotetext{
${ }^{1}$ Basta consultar a primeira história da literatura de Silvio Romero (1888) e vários compêndios e dicionários do século XIX para verificar a omissão das escritoras nas histórias atuais. Salva-se, de certa forma, a História da inteligência brasileira (1976/78), de Wilson Martins.
} 


\section{Daughters: With Reflections on Female Conduct, in the More Important Duties of} Life (1787), chamando atenção para as restrições educacionais impostas às jovens, que, ao lado de matérias voltadas para o lar, eram impedidas de ter uma instrução mais aprofundada e entrar nos mesmos cursos superiores destinados aos homens.

Ao se instituir o curso superior para as mulheres, tais instituições eram só para o sexo feminino, e seu currículo era diferente do currículo das escolas superiores destinadas aos homens. Essa desigualdade de oportunidades e de direitos entre homens e mulheres ainda estava presente nas primeiras décadas do século XX, na Inglaterra, como retrata e denuncia Virginia Woolf, em seu livro-ensaio Um teto todo seu (1928), extraído das duas conferências que realizou na Sociedade das Artes e publicado em 1928, cujo público era inteiramente formado por mulheres.

Voltando ao livro Uma defesa dos direitos da mulher (1792), sua autora já mostrava que só a educação, e uma educação igualitária na formação de ambos os sexos, era o caminho para a mulher conquistar melhor situação econômica, social e política. No livro anterior, ela já alertava para a impregnação, na mente das moças, de só cuidar de sua aparência e, neste, ela avança, defendendo a instrução como a possibilidade de a mulher escapar de uma sociedade sexista, sem viver submetida ou escravizada, e de serem, como ela chamava as mulheres casadas, "escravos-convenientes". As propostas contidas no seu livro eram pertinentes ao período, pois estavam dentro do contexto das discussões sobre os Direitos do Homem, polemizando com Rousseau sobre as ideias contidas em Emile e no Contrato Social(1762). Assim, Wollstonecraft propugnava que as mulheres se engajassem no projeto ilustrado e reformador da sociedade, que se delineava. As ideias escritas há mais de 250 anos ainda são pertinentes e atuais, principalmente nessa contemporaneidade líquida ${ }^{2}$

O livro de Mary Wollstonecraft repercutiu no mundo ocidental e teve muitas traduções ao longo de um século, sendo retomado vigorosamente na primeira onda feminista, o movimento sufragista.

\footnotetext{
${ }^{2}$ Uma dessas reflexões pode ser confrontada com as práxis sociais do momento: A mentalidade feminina fora relegada, pela tirania masculina, ao limbo da fatuidade a que as mulheres, em geral, acabaram por se adaptar. E as mulheres que hoje reclamam direitos, devem saber que a estes correspondem deveres, assim como a rebelião contra a dominação masculina se deve realizar em nome dos valores universais.
} 
No Brasil, recém-saído da situação de Colônia, com suas instituições ainda débeis e, contraditoriamente, um país escravagista, Nísia Floresta vai fazer uma tradução livre, agregando também suas reflexões sobre as condições das mulheres no Brasil. As regiões através das quais as novas ideias de liberdade entraram foram os locais onde se fundaram faculdades - Recife, Salvador, São Paulo e Rio de Janeiro. Nísia Floresta Brasileira Augusta, mais conhecida por Nísia Floresta, que era o pseudônimo de Dionísia Gonçalves Pinto (18101885), era filha de rico negociante do Rio Grande do Norte, mas, ainda pequena, seu pai se transferiu para Recife. Vivenciando essa efervescência com os jovens estudantes de Direito, essas novas ideias devem ter levado-a a conscientizar-se de suas próprias limitações no espaço público. Retomando o livro inglês como inspiração, Nísia Floresta acrescentou suas reflexões sobre a situação da mulher no Brasil, insistindo em sua instrução mais aprofundada, semelhante à dada aos homens. Direitos das mulheres e injustiça dos homens saiu pela primeira vez em $1832^{3}$. Sua autora é considerada a pioneira do feminismo no Brasil com esse livro. Sua carreira se desenvolveu não só na literatura, escrevendo poesias, mas também no jornalismo, com artigos para os jornais. Também fundou escolas para moças, tanto no Rio quanto no Rio Grande do Sul por onde passou. Destemida, conviveu com intelectuais, e chamo atenção para o poema "A lágrima de um Caeté" $(1849)^{4}$, hoje esquecido, mas que se engajava na esteira do nacionalismo do contexto da época, sobre a identidade do País com sua gente, tomando a batalha de Pernambuco como foco de insurreição libertadora da pátria.

A educação das mulheres da época terminava no primário, mas nem sempre elas frequentavam escolas, pois muitas delas viviam em fazendas e engenhos fora do centro da cidade. Algumas delas eram internas em colégios de freiras, mas nem sempre concluíam seus estudos. Os estudantes de Medicina foram disseminadores indiretos (sem intenção) da instrução das mulheres. Assim, elas aumentavam seus conhecimentos sendo autodidatas, lendo livros de bibliotecas de parentes ou solicitando alguns livros daqueles que frequentavam

\footnotetext{
${ }^{3}$ Para melhor conhecimento das atividades, pensamento e atuação de Nísia Floresta, recomendo a leitura do livro de: DUARTE, Constância Lima. Nísia Floresta: vida e obra. Natal: Editora da Universidade Federal do Rio Grande do Norte, 1995.

${ }^{4}$ O poema foi republicado por Constância Lima Duarte. Uma visão rápida sobre a escritora pode ser encontrada em: MUZART, Zahidé L. (Org.). Escritoras brasileiras do século XIX. Florianópolis: Ed Mulheres/ EDUNISC, 1999. p.175-193.
} 
a faculdade. Observe-se que na época, entre as artes, a literatura era bastante lida e exercitada pelos jovens estudantes, que, na maioria, não iriam exercer a profissão ${ }^{5}$.

Já se percebem, portanto, as limitações sociais que impedem a liberdade e a igualdade entre os dois sexos. Encaminhadas para o papel de esposa e mãe, os espaços possíveis de ocupação das mulheres era dentro de casa e seu entorno. Assim, mesmo que elas exercitassem no seio da casa seus poemas ou romances, outro impedimento aparece. A mulher casada não podia publicar, principalmente porque a mulher não poderia receber os recursos econômicos da venda de seu trabalho. Mas a pior das limitações estava no bojo do próprio movimento romântico. Voltado para expressar os sentimentos, a subjetividade do escritor, sua temática louvava o amor de uma mulher, a natureza grandiosa e virgem das florestas.

No caso da escrita da mulher, como ela poderia se expressar? A baiana Adélia Fonseca (1827-1920), sendo uma das primeiras escritoras do período romântico e começando a escrever na transição do arcadismo e romantismo percebeu os limites. Em mais de um poema, ela reage a essas restrições. Participante dos grupos intelectuais da época, considerada grande poeta, só na fase da maturidade, instada por críticos seus amigos e os mais importantes da cidade, resolve publicar sua produção. Nela se vê a longa trajetória, inclusive traçada entre o soneto clássico e os poemas mais livres. No entanto, logo no "Prólogo", de seu único livro Ecos de minh'alma (1866) percebe-se a limitação não só de vir a público, mas a dificuldade de escrever dentro dos paradigmas românticos, que ela ainda alcançou por muito tempo.No "prologo", além de assinalar os nomes dos críticos que a incentivaram, destina todos os recursos financeiros advindos da sua compra para as famílias que perderam seus provedores na Guerra do Paraguai.

Chama a atenção, para um/a leitor/a arguto/a logo de início, a estratégia que as mulheres teriam que ter para se expor em público, isto é, publicar sua produção em livro. Essa produção deveria ser legitimada por críticos e poetas, mesmo que a autora, como é o caso de Adélia Fonseca pertencer a uma das mais tradicionais famílias baianas.

O segundo limite para chegar ao ambiente público, também convencionado para a mulher, estava no impedimento de receber os recursos provenientes da venda de seus livros.

\footnotetext{
${ }^{5}$ Basta observar os títulos das teses da Faculdade de Medicina da Bahia, bem como dela saíram inúmeros escritores, críticos, jornalistas, deputados, que nunca exerceram a profissão. Um título de curso superior, pelo menos no Brasil, catapultava esses profissionais para outros encargos, mais distintos do que exercer a profissão somente. Basta ler Memórias póstumas de Brás Cubas(1881), de Machado de Assis. Vide as peças teatrais do mesmo autor (Obras completas, Editora Aguilar, v.II, 1962).
} 
Era, na época, vedado às mulheres de classe alta (e também aquelas provenientes dos estamentos médios) ganhar dinheiro, e uma publicação destinada a livrarias representava a transgressão de duas normas: ultrapassar os limites do espaço privado e a possibilidade de receber recursos de sua própria produção. Daí, a vendagem destinar-se às famílias vítimas da Guerra do Paraguai.

Mas o desapontamento da autora com os limites impostos pela própria arte aparece em algumas de suas produções, como em um poema no qual, explicitamente, ela troca o eu poético do feminino para o masculino para poder elaborar um poema de amor. Em outros poemas, como era vedado à mulher declarar o amor a um homem, seus poemas falam de um passado ou de uma distância entre os dois amados que cria a saudade do tempo em que estavam juntos.

Assim, apesar da imposição desses limites na época da liberdade, torna-se difícil perceber ou visibilizar a violência contra a mulher quando se trata das artes e da literatura (sem falar da sua vida privada).

O universo romântico, com suas valorações, referenciais simbólicos e temas eleitos, ancoram e fundamentam (apenas) o discurso do poeta homem. Em outras palavras, a produção da época, os temas circulantes em torno da angústia (existencial ou vivencial), o amor em suas frustrações: o sofrimento de amor ou o amor não correspondido, a mulher inalcançável, ou a visão da natureza, sempre expressos pela visão interior do poeta, não poderiam ser o discurso das poetisas, desde que sua imagem/representação - como anjo, futura mãe de família e esposa - seria contraditória à sua configuração. Esse universo limitava a expressão da poetisa, obrigando-a, se quisesse escrever, em seu gineceu, as fronteiras de seu jardim ou pomar de sua casa. Daí, tantas evocações a flores, passarinhos, dia e anoitecer. Um vocabulário limitado e um campo simbólico finito. Às mulheres, o mundo, a natureza frondosa, o mar em suas vagas tempestuosas era interditado.

Mas, no entreato do final do romantismo e do início do realismo no País ou melhor, entre 1860 e 1890, as escritoras começaram a criar estratégias para fazer circular suas produções, poemas, romances e contos, através de um contra-discurso ${ }^{6}$. As primeiras estratégias foram a criação de revistas que circulavam nas regiões que, muitas vezes,

${ }^{6}$ Para verificar escritoras baianas do final do século XX e início do século XX, vide: < http://www. escritorasbaianas.ufba.br/index $2 . h t m l>$. 
alcançavam o território nacional. Também se inseriram em publicações como almanaques, editados em Portugal ou mesmo no País. Além disso, começaram a tentar, protegidas por maridos intelectuais, a escrever em jornais de grande saída. Nessa última situação, estão centenas de escritoras, inclusive baianas - escrevendo romances, crônicas ou poemas seja em jornais, seja em Almanaques, seja em livro - aparecem as romancistas baianas Ana Ribeiro e Inês Sabino e as poetisas Amélia Rodrigues e Ana Autran. Quando se aventuravam a sair, individualmente, do espaço doméstico, a maioria utilizava-se de pseudônimos ${ }^{7}$. As primeiras, eram filhas de famílias de renome e riqueza, já no meado do século XIX também aparecem escritoras dos estamentos intermediários ${ }^{8}$.

Proveniente dessas camadas intermediárias, o percurso literário de Amélia Rodrigues parece ser exemplar por ter sido difícil. A sua formação intelectual deve-se a ter parentes no clero, e, sendo de poucos recursos, matricula-se em uma escola regular só já adolescente, obtendo o título de professora primária. Ao realizar o concurso público para exercer a profissão, alcançou o primeiro lugar no Estado, passando a ensinar em uma escola nos arredores de Santo Amaro. Logo, os habitantes da cidade constatam sua inteligência, audácia e versatilidade pelos poemas publicados no jornal local Eco Santamarense. Sua estreia se deu com a composição de um pequeno livro de poemas, intitulado Filenila (1883). Mas o que lhe abriu as portas da cena literária foi o teatro, com a peça intitulada Fausta (1886) ${ }^{9}$.

É interessante relembrar a vida dessa escritora - de professora primária do interior à escritora e editora da revista Leituras Católicas $^{10}$, publicada pelos Salesianos - porque ela consegue criar estratégias para se inserir na cena literária, embora não tenha tido o auxílio de um nome de prestígio ou críticos para legitimá-la.

\footnotetext{
${ }^{7}$ Muitos desses pseudônimos não foram recuperados por não constar de dicionários.

${ }^{8}$ Em uma sociedade regida pela escravatura, identificamos dois segmentos sociais bem determinados: donos de terras e escravos. O miolo da sociedade, formado por funcionários e pequenos comerciantes, ainda não pode ser considerado de classe média, visto que a sociedade agrária predomina sobre a vida urbana.

${ }^{9}$ Ainda não foi encontrado o livro Filenila, mas, no seu acervo, guardado por Henriqueta Catharino, encontrouse o manuscrito da peça Fausta, a qual foi publicada no livro organizado por Ivia Alves com o título Amélia Rodrigues: itinerários percorridos (Santo Amaro: NICSA; Salvador: Quarteto, 1998). As produções lírica, teatral e ficcional, principalmente, o romance $O$ mameluco, foram estudada por Milena Britto no seu doutorado, mas ainda esta produção não foi publicada.

${ }^{10}$ A publicação da revista intitulada Leituras Católicas tem início com a chegada dos Irmãos Salesianos no país, em 1883. Tendo sua sede em Niterói, logo implantam sua editora para combater a entrada de outras religiões como a protestante (como eram chamadas então). Amélia Rodrigues começa a colaborar com a revista em 1893, com uma série de crônicas, sob o pseudônimo de Dinorah.
} 
Amélia Rodrigues, enquanto morou em Santo Amaro, teve acesso ao jornal local, onde publicou inúmeras poesias e o romance Mameluco $(1882)^{11}$, que saiu semanalmente. Seu tema aparece como uma provocação ou reivindicação de que a terra deveria ser dos brasileiros e não de estrangeiros. Com esse assunto, ela mostra a crueldade dos donos de escravos em suas propriedades, a luta pela terra entre os donos de engenhos e as formas desiguais e escusas de se tomar posse de bens de brasileiros. A estrutura é bastante similar aos romances românticos nacionais, tendo feito um cruzamento de A moreninha e uma resposta ao descendente, Moacir, de Iracema. De A Moreninha, aparece a lenda que dá origem ao personagem principal, o mameluco, contada em versos e em um tempo passado. O português, que tem terras, casa com uma índia. O filho mestiço, após a morte dos pais, por injunções do grupo de senhores locais, tem suas terras e tem de trabalhar para esses senhores de terra, no entanto prefere ir lutar na Guerra do Paraguai. Com esse personagem, um descendente híbrido, espoliado de seus bens, a autora denuncia como estavam vivendo os descentes de Iracema, que, para Alencar, seriam os donos da terra.

Amélia Rodrigues, em suas primeiras produções, investe contra a sociedade escravocrata, tendo mais de uma obra que trata os escravos de forma igualitária aos brancos. Sua peça Fausta trata dessa temática. Na época, os donos de terra eram contra a instrução de escravos, por considerá-los broncos e impossíveis de assimilar qualquer educação. Na peça Fausta, filha e herdeira de um dono de terra, tendo morrido o pai, vai seguir os conselhos do escravo Lúcio, amigo e criado junto com o pai. Educado e instruído, é Lúcio quem vê a armadilha em que a jovem Fausta vai cair ao querer casar com um italiano. A autora, com a peça, revela o preconceito daquela sociedade, ao mesmo tempo em que mostra que todos os homens, independente de raça e classe, são iguais.

Mas as águas claras e mansas que envolviam a produção da escritora, deixando-a livre para colaborar em vários jornais, inclusive os da Capital (usando pseudônimos), tornaram-se densas com a morte do pai e sua vinda para Salvador. As portas se fecharam e, por mais de três anos, ela não viu nenhuma de suas produções publicadas. A única estratégia possível para ela, visto que não tinha nome de família nem reconhecimento dos críticos locais, foi buscar a proteção da Igreja.

\footnotetext{
${ }^{11}$ Devo a informação da existência do jornal Eco Santamarense no amo de 1882, onde se encontra ao longo do ano os capítulos do romance $O$ Mameluco a minha colega Profa. Dra. Susana Alice Cardoso a quem muito agradeço a preciosa informação.
} 
Assim, em 1893, aparecia em Leituras Religiosas, uma nova revista fundada pelos irmãos salesianos, a primeira "Carta a uma amiga". Na realidade, eram crônicas nas quais a escritora Amélia Rodrigues (sob o pseudônimo de Dinorah) tratava de variados temas da sociedade para sua fictícia amiga Artêmia, que se tinha tornado freira. Foram a solução e a estratégia encontradas por Amélia Rodrigues, o que lhe rendeu poder escrever, mas nem sempre com liberdade, pois a revista católica, destinada a senhoras de família, tinha suas normas e crivos, tendo a escritora deixado de lado a sua potencialidade de criticar a sociedade da época.

No entanto, protegida pela Igreja, a criação em versos extrapolava todas as normas da Igreja. É verdade que ela já vinha se exercitando em trabalhar com um contradiscurso desde jovem, porém agora era a saída. Dois veios temáticos atravessaram seus poemas até a publicação de Bem-me-queres (1906), quando ela reúne quase toda a sua produção até aquele momento. No primeiro tema, o poema "A pétala de rosa", publicado originalmente no periódico Eco Santamarense, em 1884, quando ela tinha 23 anos, a poetisa desenha um diálogo entre a voz dominante e a voz submetida.

Metaforizados em pássaro e pétala de rosa, o pássaro admoesta a pétala que está fora do lugar, desejando sair, voar e conhecer outras coisas, e diz que ela é uma louquinha, pois lá fora, a ventura é sempre enganosa e mentirosa. Finalmente, concluindo sua advertência, ele lhe dirá que tal atitude a levará ao mau caminho e à lama. Estando, logo depois com sede, o pássaro se acerca da água de um rio e vê a pétala desfalecida às margens. O pássaro a reconhece e diz:

\footnotetext{
"Oh, ei-la!"... em suspiros lhe disse o piedoso

Gentil beija-flor

"O vento matou-a..." responde-lhe a mísera:

"Oh! Não!... foi a crença na força do amor!"...(1998:97-98)
}

Nem se precisa evidenciar que tal diálogo e a escolha dos elementos beija-flor e pétala de rosa são constructos semânticos e referem-se à representação de um homem e de uma mulher, bem como o desejo de ir além do espaço delimitado para ela difere de longe do espaço pertencente ao homem, lembrando o espaço público e o privado. Mas a ideia central aqui é a tentativa da pétala de querer ultrapassar os limites, e, apesar de desfalecida, ela considera que valeu a pena. 
Já a segunda temática, como em "Clamor inútil”, escrito na maturidade, expressa uma angústia (de não poder se expressar de forma autêntica):

Meu coração de há muito estava morto,

Mas a enterrá-lo eu não me decidia;

Meti-o no caixão fúnebre, um dia,

E disse-lhe: - "Aí está, chegaste ao porto!..."

Armei-lhe um catafalco em negro horto

E um círio lhe acendi, donde corria

Uma lágrima longa, triste e fria:

- O círio da saudade sem conforto!

Por que o não enterrei de todo?... Agora

$\mathrm{O}$ velho preso a debater-se chora

Como um doido, entre as tábuas do caixão...

Desgraçado! não tens direito ao gozo

nem à vida! não chores mais teimoso!

Morre por uma vez, meu coração. (1998:97-08)12

Se, no primeiro poema, a escritora desafia as regras sociais, ultrapassando os limites impostos pelo discurso autoritário que delimita o espaço da mulher, no segundo, permite desnudar o sentimento de angústia que a envolve. Essa ideia de que a escritora (ou a mulher) não exprime, realmente, o que pode expressar, sem ter maiores consequências para si e para sua produção, cada vez mais se firmará em várias poetisas, culminando na obra de Cecília Meireles, com o "Epitáfio de uma navegadora" ou em "Retrato". O contradiscurso, portanto, estava construído e, se elas não podiam se expressar abertamente, nada podia deter a angústia de não poder ser um todo integral.

E a liberdade, cortada da mulher na literatura, abria-se quando ela passava para falar em palestras e discursos. De acordo com discursos recolhidos de Amélia Rodrigues, percebe-se que ela não mudou sua visão de mundo, mas, para sobreviver dentro de tantas interdições, mudou de atitude.

12 De certa maneira, vários poemas de Cecilia Meireles expressam, também, metaforicamente essa angústia, como em "Retrato" (“- Em que espelho ficou perdida/ a minha face?”) e "Epitáfio de uma navegadora" ("Eu não pude conhecê-la,/ sua história está mal contada,// mas seu nome, de barca e estrela,/foi: SERENA DESESPERADA"), entre outros poemas. (Cecília Meireles: obra poética) Aguillar, 1972. 
No caso das romancistas, embora o romance e o narrador se desprendessem de quem estivesse escrevendo, a criação podia seguir o ethos da época, porém o controle estava no vocabulário empregado. Mas nem sempre a perspectiva do olhar coincidia com a escolha masculina do narrador que endeusava as mulheres e as descrevia nos mínimos detalhes, encerrando seus romances com o casamento. Contraditoriamente ao paradigma romântico, as romancistas como Inês Sabino e Anna Ribeiro preferiam tematizar o casamento, o "depois que as cortinas se encerram". Consolidado o casamento, as protagonistas das autoras são verdadeiras heroínas porque, na maioria das vezes, ou elas foram enganadas por causa da fortuna que tinham, ou os maridos se voltavam para o jogo desenfreado, perdendo a fortuna de ambos, ou, depois de separadas por anos, voltavam os maridos pobres e doentes para o cuidado delas.

Assim, enquanto os escritores idealizavam todos os rituais do amor até o casamento, as mulheres viravam a moeda e mostravam o cotidiano nada feliz de um casal. Inês Sabino, em Lutas do coração (1898), trata de um jovem brasileiro educado à moda antiga, pois tinha estudado advocacia em Portugal, que se apaixona à primeira vista por uma bela mulher. No caso, essa mulher era separada (não havia desquite nem divórcio na época) e, por causa desse entrave, o jovem, mesmo profundamente apaixonado, prefere casar-se com uma virgem, a filha de um amigo de seu pai: jovem e virgem. Em um único romance, ela denuncia a condição da mulher separada, que não terá possibilidade de uma vida afetiva estável, tornando-se apenas a amante, e, de outro lado, demonstra os casamentos de conveniência e sem amor, prendendo uma jovem virgem e desposável, a legítima mulher para as regras da burguesia, que terá o papel de esposa e mãe. Mas ela não vai estruturar seu romance para a vitória do amor e do casamento, como José de Alencar fez em seu romance Senhora, Inês Sabino mostra-se mais desencantada com a sociedade e com o casamento, como o fez Machado de Assis com seu romance de estreia Ressurreição (1872). Embora as tramas sejam semelhantes, elas divergem porque Lívia é viúva. É o olhar desencantado tanto do escritor quanto da escritora sobre essa nova sociedade e os arranjos que ela fomenta, que constituem o foco das tramas de seus romances.

Há muitas escritoras que, embaladas pelo nacionalismo (a entrada firme do Positivismo no país) e pela limitação dos estudos femininos, porque não podem entrar nas faculdades escrevem poemas, romances e peças teatrais, evidenciando a importância da educação. Nesse período, estava havendo transformações drásticas na economia brasileira, como o interesse 
pelo café e a decadência dos engenhos de açúcar, a libertação dos escravos, colocando à míngua, de um dia para outro, vários donos de terras e suas famílias, principalmente no recôncavo baiano. Mulheres que eram ricas tornavam-se inesperadamente desamparadas, seja pela perda econômica, seja pela perda do marido e as solteiras ficavam totalmente desvalidas. Amélia Rodrigues escreveu um texto híbrido, porque é uma ficção entremeada de situações explicativas e didáticas sobre o valor da educação das meninas, de forma igualitária aos meninos. Mestra e mãe (1898) ${ }^{13}$, que por muito tempo foi adotado oficialmente no currículo do primário até o meado dos anos 30, trata de uma viúva cearense que, tangida pelos efeitos da seca, depois de ter perdido marido e filhos, encontra amparo na casa de um senhor de terras. No entanto, ela não quer viver de favor e propõe abrir uma escola para crianças. Sabendo dominar um currículo primário, ela vai-se tornando importante para aquela cidadezinha ao dar instrução àquelas crianças. Na realidade, a escritora não via razão para a mulher ser amparada por alguém, já que, se tivesse instrução, ela poderia se sustentar sem solicitar a compaixão de parentes ou estranhos.

Essa sensação de limitação está explicitamente declarada em produções do período dito realista e naturalista, como no romance Lésbia (1890), de Délia (pseudônimo da riograndense-do-sul Maria Benedita Câmara Bormann) $)^{14}$.

Lizir Arcanjo Alves, em seu livro Mulheres escritoras na Bahia (1999), recupera um desabafo de uma jovem escritora sobre a limitação da possível criação realizada por mulheres:

Em 1879, uma poetiza do Rio Grande do Sul, Anália Vieira do Nascimento, resume o conflito por que passava uma mulher para definir o rumo certo de sua literatura, num poema dirigido a Antonio Xavier Rodrigues Cordeiro, editor do Novo Almanach (sic) de Lembranças Luso-brasileiro. Conta ela que, tendo abandonado as charadas e os logogrifos, viu-se dividida entre as escolas lírica ou realista. Porém, se à primeira dedicasse os seus cantos, diriam: Criancices! o romantismo morreu!"; se voltasse seu canto para o povo, seria chamada de comunista e petroleira, se pensasse em seguir à moderna poesia científica, não teria condições porque não havia frequentado academias, nem liceus. Diante de tudo isso, desabafa: "As grandes alturas, vedadas me são, bem sei;/ caminharei nas planuras/ e disso não passarei!"; e

\footnotetext{
${ }^{13}$ Editada pela iniciante Editora Vozes de Petrópolis, dos padres Beneditinos. A editora situava-se em Petrópolis, daí o primeiro nome vai ser esse, atualmente, apenas Editora Vozes.

${ }^{14}$ Esse romance foi republicado pela Editora Mulheres e a introdução, escrita por Norma Telles, está disponível em: < http://www.editoramulheres.com.br/intro14.htm $>$.
} 
conclui que a sua sina era mesmo a de ser logogrifista. ${ }^{15}$ (ALVES, 1999, p.26-27).

As escritoras, na sua maioria, diante de tantos entraves, resolviam escrever dentro das normas determinadas para elas, cujas temáticas "nobres" eram os sentimentos de ser mãe, o amor à pátria, a beleza de delicadeza das flores, dos pássaros e o pomar. Não podendo ensejar voos mais altos sobre o amor ou o desejo, poucas conseguiram inovar em suas criações, exceto aquelas que metaforizaram a natureza ou trataram de suas angústias como poeta. Mas tal estratégia vai aparecer no início do século XX. Algumas das representantes baianas desse veio metafórico serão Maria de Lourdes Bacelar, Seleneh Medeiros e também, nos contos, Elvira Foeppel.

Compreendendo que os costumes sociais estavam aprisionados pelo discurso, a geração de escritoras que começa a escrever dos anos 60 e 70 do século XX, a maioria já com curso superior, profissionais e, portanto, mais avançadas nos meandros da linguagem, passa a demolir as interdições da sociedade e da cultura sexista brasileira. Não é por acaso que Myriam Fraga desconstrói, passo a passo, ou melhor, de poema em poema, o "mito"criado pelo Ocidente, da esposa fiel de Ulisses, como aparece no verso final do poema "Penélope", revelando a sua rebeldia: "Quando Ulisses chegar, a sopa está fria" ${ }^{16}$. Eis o poema:

Hoje desfiz o último ponto, A trama do bordado.

No palácio deserto ladra O cão.

Um sibilo de flechas

Devolve-me o passado.

Com os olhos da memória

Vejo o arco

Que se encurva,

A força que o distende.

\footnotetext{
15 As mulheres começaram a participar de revistas maiores na seção de Divertimento, como logogrifista, que significa construir charadas, adivinhações, como se vê no Novo Almanach (sic) de Lembranças Luso-brasileiro para o ano de 1880. Lisboa, 1879. p.228-230.

16 Vide o estudo do mito em: < http://www.abralic.org.br/anais/cong2008/AnaisOnline/simposios/pdf/060/ RICARDO_SILVA.pdf>. Acesso janeiro de 2012.
} 
Reconheço no silêncio

A paz que me faltava,

(No mármore da entrada

Agonizam os pretendentes).

O ciclo está completo

A espera acabada.

Quando Ulisses chegar

A sopa estará fria.

Também, no seu primeiro romance, O jogo de Ifá (1980), Sonia Coutinho explícita outro tipo de desconstrução. A trama trata do retorno a Salvador, após viver na cidade grande, Rio de Janeiro, de um personagem homem ou de uma personagem mulher, frustrado/a por percalços na sua vida e que retorna para casa paterna a fim de recuperar seu caminho e refletir sobre o passado. A leitura do mesmo discurso, escrito pelo homem ou pela mulher obriga o leitor a mudar de atitude. A escritora astutamente coloca as mesmas situações vivenciadas por Renato ou por Renata, utilizando-se das mesmas palavras e nas mesmas situações. A violência contra a mulher fica explicita e se é apenas um fracasso para Renato, aparece como um comportamento imoral para Renata. Com isso, ela denuncia que determinadas condutas são admissíveis nos homens, mas inadmissíveis e até censuráveis para uma mulher instruída, de classe média.

O desmonte das convenções e limitações da sociedade fica evidente nesse romance inesquecível, mas que não vem sendo lido pelos leitores, tanto que nunca passou da primeira edição. A autora notabiliza-se pelos romances, mas principalmente pelos contos em que desfaz os mitos da beleza, feminilidade e juventude ${ }^{17}$.

A segunda onda feminista proporcionou a publicação de diversas autoras, além de dar mais visibilidade àquelas que já estavam no cenário literário, ocupando-se como trama maior de seus romances a crítica aos limites sociais e artísticos, abrindo uma gama de olhares e vozes provenientes das mais diversas regiões do Brasil.

\footnotetext{
${ }^{17}$ Sonia Coutinho tem uma imensa fortuna crítica, mas chamo atenção para um dos artigos que analisam sua produção a partir de uma perspectiva feminista: <http://www.jstor.org/discover/ 10.2307/346336?uid=3737664 $\underline{\text { \&uid }=2129 \& \text { uid }=2 \& \text { uid }=70 \& \text { uid }=4 \& \operatorname{sid}=21100706694311}>$.
} 
Vale a pena lembrar, por último, a produção contundente, com uma linguagem sintética e metaforizada, de Helena Parente Cunha. A escritora aparelha seu leitor para refletir sobre comportamentos e construções discursivas, que ora são desenvolvidas em pequenos relatos, ora são enunciadas ao longo dos minicontos. $\mathrm{Na}$ verdade, tais constructos discursivos foram recebidos na infância e modelaram as limitações das mulheres.

Nos minicontos de Cem mentiras de verdade (1985), alguns dos "mitos" de comportamento criados pela família burguesa são desmontados em favor da liberdade e pensamento das mulheres. Essa voz internalizada que forja os impedimento da liberdade em torno da mulher vai-se intensificar duplicando as personalidades (em Mulher no espelho, 1982) e se fazendo em pedaços no romance As doze cores do vermelho(1989), cuja estrutura da página tripartite consegue trazer à tona as várias dobras internas nas quais as mulheres se configuram. Em Os provisórios (1980), a autora evidencia como uma mulher que tem internalizado o código patriarcal por causa das pressões externas (portanto, o conto deixa claro que é a partir dos anos de 1968/75) se comporta, age e reage:

\section{Engano}

Estava com trinta e três anos e donzela era ela. Não por convicção, pois não cabia razões, transbordava. Nem por preconceito, pois se queria isenta, ultrapassava. Mas tinha medo de engravidar. Ficar no mundo sozinha com um filho para criar. Dos seus desejos só ela sabia. Reagia. tal queria. mas não cedia. Até que um dia. Um homem que não fazia filho? Esterilidade comprovada. Garantiu. Ela se transcendeu cedeu deu. Já donzela era não ela. E era mais. Era-lhe um filho que no ventre lhe cabia. Sozinha no mundo era ela.(1990:93)

Enfim, no percurso desse artigo, evidenciei as estratégias das autoras (baianas) do século XIX -XX protegidas pelo nome ou pelas palavras de um crítico se inseriam na vida pública, bem como o percurso da geração dos anos 60/70, que com outra forma de ver a vida, tiveram formas de discursos e estratégias para demonstrar os impedimentos reais de se moverem no ambiente público: desde o desmonte do mito da mulher fiel, passando pelas construções discursivas ditas e internalizadas pela mulher desde criança ou mesmo evidenciando como a linguagem limita suas expressões e como, ardilmente, passaram a construir um contra-discurso dentro do discurso dominante. 


\section{REFERÊNCIAS:}

ALVES, Ivia (Org.). Amélia Rodrigues: itinerários percorridos. Santo Amaro: NICSA; Salvador: Quarteto, 1998.

ALVES, Ivia. Interfaces: estudos críticos sobre escritoras. Ilhéus: Editora da UESC, 2005.

ALVES, Lizir (Org.). Mulheres escritoras na Bahia: as poetisas (1822-1918). Salvador: Étera, 1999.

BRANDÃO, Izabel; ALVES, Ivia (Org.). Retratos à margem: antologia de escritoras das Alagoas e Bahia (1900-1950). Maceió: EDUFAL, 2002.

CUNHA, Helena Parente. Cem mentiras de verdade: contos.1. ed 1980/ 2. ed. Rio de Janeiro: José Olympio, 1990.

FLORES, Hilda A. Hübner. Dicionário de Mulheres. 2. ed. Florianópolis: Editora Mulheres, 2011.

MUZART, Zahidé (Org.). Escritoras brasileiras do século XIX: antologia. Florianópolis: Editora Mulheres; Santa Crus do Sul: EDUNISC, 1999.

RECEBIDO EM: 07 de maio de 2012

APROVADO EM: 08 de junho de 2012 